\title{
South Atlantic Division (SAD) Regional Sediment Management Optimization Pilot
}

\author{
by Clay A. McCoy, Jackie J. Keiser, Kenneth N. Mitchell, and Linda S. Lillycrop
}

PURPOSE: The US Army Corps of Engineers (USACE) South Atlantic Division (SAD) Regional Sediment Management Optimization Pilot (RSM-OP) Tool was developed and implemented under a pilot effort to help define sustainable solutions across USACE missions and to support regional implementation strategies across project business lines. The goals of the RSMOP are to (1) develop and provide an actionable and optimized Regional Sediment Management (RSM) strategy on a USACE division scale that will most efficiently execute the Navigation (NAV) and Flood Risk Management (FRM) Business Line budgets and (2) maximize the amount of dredging while also increasing the amount of RSM opportunities implemented to create value to the nation. Value created and funding saved as identified through the RSM-OP will allow the USACE to execute a greater number of projects under flatlined or reduced budgets. While RSM principles and strategies have been explored and implemented in many USACE districts, the RSM-OP is the first comprehensive approach to define and optimize RSM opportunities for coastal NAV and FRM projects and to quantify economic benefits across a USACE division.

BACKGROUND: The total volume of USACE dredging has remained relatively stable over the past several decades, but the cost of dredging has increased substantially. As a result of increased costs and constrained budgets, there are extensive NAV and FRM remaining needs within the USACE and SAD. While RSM principles and strategies have been explored and implemented in many districts, the USACE has not taken a comprehensive approach to define and optimize RSM opportunities for coastal NAV and FRM projects or quantify economic benefits across an entire division. By placing beach quality material dredged from navigation projects onto adjacent beaches, the USACE Jacksonville District (SAJ) estimated \$27 million of economic value associated with implementing and executing RSM strategies for the 2013 Flood Control and Coastal Emergencies Act projects within SAJ. Estimated value was calculated by multiplying the total volume of material placed on shore protection projects (beaches) by typical costs per cubic yard to obtain the sediments from borrow sites for the individual projects. This simplistic approach documents significant value by estimating onetime value to the shore protection projects but does not account for numerous other areas of value to both the NAV and FRM programs.

Economic value for FRM and NAV projects can result when a NAV project uses the FRM project as a placement area or when a FRM project uses a NAV project channel(s) as a material source (Smith et al. 2006). Benefits include a reduced number of dredge mobilizations, conserved capacity of sand sources and placement areas, potential maintenance of low priority channels, advanced maintenance of navigation channels, and life-cycle value associated with FRM projects. In some cases, placement of beach-quality material from NAV projects onto FRM projects can eliminate the need for the individual FRM project or, conversely, the need to dredge NAV projects with district Operations and Maintenance funds. 
Another area of value associated with RSM, although difficult to quantify, is the principle that sediment is a valuable resource and should be maintained in the active sediment littoral system. For example, if dredged material that is suitable for placement on a beach, in a nearshore environment, or for another beneficial use is disposed in a Dredged Material Management Area (DMMA) or Ocean Dredged Material Disposal Site (ODMDS), the value of the material is essentially lost because recovery of the material is not economical in most cases. Maintaining sediment in the active sediment littoral system increases resiliency of communities throughout the United States where sea-level rise, subsidence, and sediment-starved coastlines threaten vitality and viability.

Purchasing, permitting, developing, and maintaining (e.g., for ODMDS, hydrographic surveys and sediment testing; for DMMA, dike raising, off-loading, cutting grass, and removing debris) both of these types of disposal options is expensive and time consuming. By assuming that every cubic yard of dredged material placed on a beach, in a nearshore area, or within another beneficial use location saves the equivalent capacity at a placement area, life-cycle benefits for the placement areas can be estimated. Value associated with conservation of placement areas is high and will only increase considering the increasing cost of real estate adjacent to navigable waterways and estuaries in addition to the increasing costs to permit and maintain the placement areas. The RSM Program is currently evaluating the true cost of upland and offshore placement (Summa ${ }^{1}$ presents $^{-}$ initial methods and analysis). Upon completion, the total cost of permitting and maintaining offshore and upland placement sites will be incorporated into the total project costs, and the RSM value will be reassessed. Throughout SAD, RSM projects are generally comparable in price to traditional projects. By updating total project costs to include offshore permitting, upland permitting, and maintenance, there is a high likelihood that the RSM projects will become the least-cost alternative.

Quantification of environmental benefits as a result of beneficially using dredged material is difficult. Environmental benefits that arise from incorporating RSM into projects include developing island habitats, enhancing wetland/marsh habitat, filling relic dredge borrow areas, developing seagrass beds, and maintaining beaches for a variety of habitats including bird and sea turtle nesting. Environmental benefits and ecosystem value are based on replacement costs (e.g., mitigation banks) or total economic value that includes use value (direct and/or indirect) and nonuse value (option, bequest, existence). Valuation of environmental resources is a growing discipline with numerous approaches and methodologies to assess value (Pendleton 2009; National Ocean Economics Program 2015). Value associated with environmental benefits is calculated based on the difference in placement costs relative to offshore or upland placement options, when appropriate. Additional environmental value could be estimated based on quotes from local mitigation banks for comparable habitat. The RSM-OP does not attempt to quantify total environmental benefits and, as a result, underestimates the total value provided by RSM.

This RSM-TN documents RSM opportunities that have been implemented throughout SAD and additional RSM opportunities that have been identified by individual districts in coordination with the RSM Regional Center of Expertise. This RSM-TN also estimates value associated with RSM

\footnotetext{
${ }^{1}$ Summa, Eric P., John L. Childs, Tony W. Ledford, John W. Bearce, Clay A. McCoy, Jackie J. Keiser, Samantha J. Borer, J. Aaron Lassiter, Jason S. Harrah, and Linda S. Lillycrop. In preparation. True Cost of Dredged Material Management: Jacksonville Harbor Case Study. ERDC RSM Technical Note. Vicksburg, MS: US Army Engineer Research and Development Center.
} 
projects relative to traditional independent projects, thus documenting the value to the nation provided by RSM and potential areas for increased efficiency.

In support of the RSM-OP, a Dredge Fleet Assignment/Scheduling Optimization model for SAD was developed to enhance the efficiency of dredge scheduling and to minimize dredging costs. A web tool was developed that incorporates all data provided in the RSM-OP development and provides the user with an interactive interface to review and manipulate project-level data. The web tool is available at the USACE Navigation Portal at http://navigation.usace.army.mil.

METHODS: A template was developed to define all potential placement options for dredged material from NAV projects and source material for all Flood and Coastal Storm Damage Reduction projects within SAD and to capture cost and relevant environmental/permitting data for each project. The goal of the template was to develop a consistent approach to defining RSM opportunities and quantifying value across regional sediment systems that vary significantly in size, geomorphology, hydrology, sediment dynamics, and management approaches. The template was divided into three sections (Project Data, Cost Engineering Data, and Environmental/Permitting Data). The major categories under each section are provided in Table 1. In general, project information was provided by project managers, operations managers, and engineering technical leads. The cost engineering information focused on dredge contract data provided by cost engineers, and environmental/permitting data were provided by project managers and planning personnel. The template is appropriate for the majority of projects within SAD but is not a perfect fit for all projects. For projects that were not a perfect fit for the template, appropriate information was gathered from individual districts to ensure sufficient information related to RSM projects was collected and associated value was estimated.

\section{Table 1. List of data inputs for RSM-OP template to define RSM opportunities and quantify value of implemented RSM projects and potential RSM opportunities.}

\begin{tabular}{|l|l|l||}
\hline Project & Cost Engineering & Environmental/Permitting \\
\hline Project Name & Cost Per CY (dredge and place) & Shovel-Ready? \\
\hline Type of Material and Location & Mobilization/Demobilization Costs & Time to Shovel-Ready \\
\hline Dredge/Nourish Interval & Total Contract Costs & Cost to Shovel-Ready \\
\hline Most Recent Year of Activity & Dredge Type & Dredging Windows/Restrictions \\
\hline Borrow/Placement Options & Cost Assumptions & Year Permitted \\
\hline & & Year Expires \\
\hline
\end{tabular}

After completing the template for all projects in a region, beneficial uses of sediments by sediment type (e.g., beach quality, nearshore quality, other-silt, mud, clay, rock) were determined, and the value of the RSM beneficial use options was estimated relative to traditional placement options (e.g., DMMA, ODMDS). Additional estimates of value were calculated based on the onetime value of material placed on a beach or nearshore environment (traditional cost per cubic yard $\times$ volume placed), and the life-cycle benefits associated with the beneficial use placement (e.g., extending dredging or nourishment intervals). Several projects throughout SAD do not have traditional offshore or upland placement options, and the only economically viable placement option is beneficial use (open water, beach, nearshore). In these particular cases, the beneficial use strategies are highlighted, but RSM value was not quantified. 
Fact sheets were developed documenting the information obtained for each project. Data tables were developed for all projects and were color-coded to correspond to RSM preferred and nonpreferred source-to-placement areas diagrams provided in each project fact sheet (Figure 1). Preferred RSM pathways are illustrated in green. Non-preferred pathways are illustrated in red.

An example of value relative to traditional placement options is provided in Figure 1 and Table 2. Beach quality material is dredged annually from Kings Bay and placed in an ODMDS at an estimated cost of $\$ 6.5$ million, and the Nassau County Shore Protection Project (SPP) (FRM project in SAJ) is nourished from an offshore borrow source every 8 years at an annualized cost of $\$ 1.7$ million, for a combined annual cost of $\$ 8.2$ million (Non RSM 1). The RSM 1 option is to place the beach quality material dredged from the channel onto the Nassau County SPP at a cost of $\$ 7.6$ million annually. The RSM 2 option is to distribute the beach quality dredged material between the Nassau County SPP and Fort Clinch, a Civil War-era cultural resource managed by the Florida State Parks system. By utilizing both of the RSM options, SAJ realizes an estimated annual value of $\$ 1.2-1.3$ million as a result of beneficially using dredged material. The value in this particular case is primarily from eliminating a mobilization and most contract costs associated with the FRM project and by minimizing the in-house labor to plan and execute the separate projects. In this situation, effective resource management reduces, and likely eliminates, the need for the traditional Nassau County SPP.

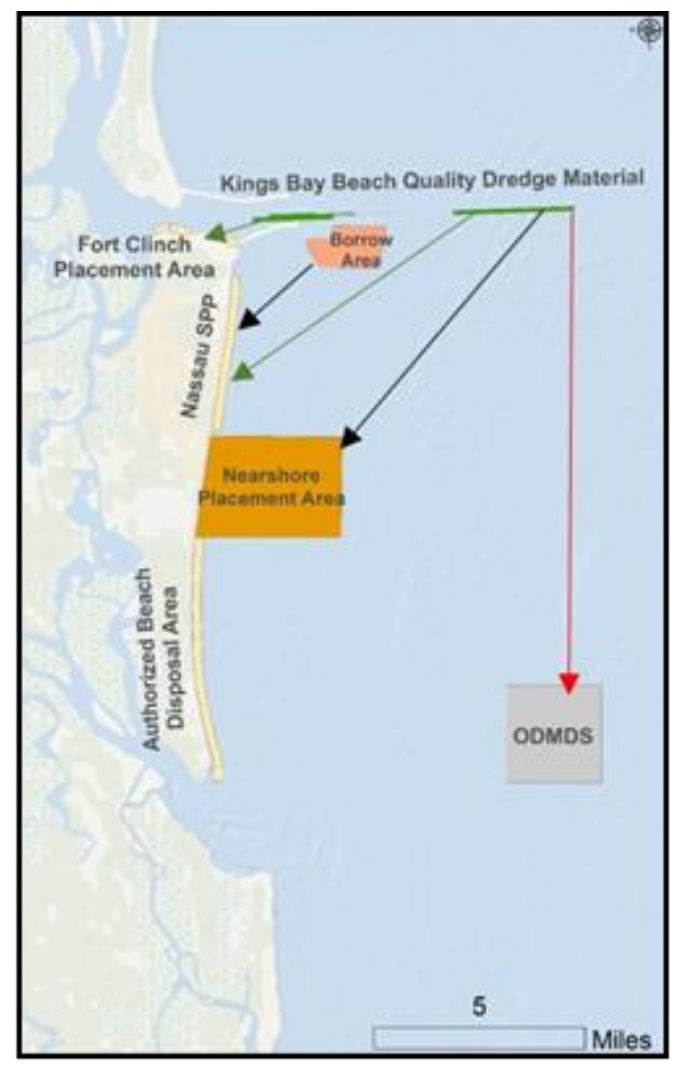

Figure 1. Standard source-to-sink diagram (Kings Bay-Nassau County) documenting RSM preferred (green arrows) and non-preferred (red arrow) strategies. 


\begin{tabular}{|c|c|c|c|c|c|c|c|c|}
\hline $\begin{array}{l}\text { Project } \\
\text { Type }\end{array}$ & Source to Sink & $\begin{array}{c}\text { Interval } \\
(Y r)\end{array}$ & $\begin{array}{c}\text { Cost } / C Y \\
\$\end{array}$ & $\begin{array}{c}\text { Volume } \\
\text { (CY) }\end{array}$ & $\begin{array}{l}\text { USACE } \\
\text { Labor } \\
(\$ \mathrm{M})\end{array}$ & $\begin{array}{c}\text { Mobilizatio } \\
n \\
(\$ \mathrm{M})\end{array}$ & $\begin{array}{l}\text { Total } \\
\text { Project } \\
\text { Cost } \\
\text { (\$ M) }\end{array}$ & $\begin{array}{c}\text { Annualized } \\
\text { Project } \\
\text { Cost } \\
\text { (\$ M) }\end{array}$ \\
\hline NAV 1 & $\begin{array}{l}\text { Kings Bay to } \\
\text { ODMDS }\end{array}$ & 1 & $\$ 14$ & 237,000 & $\$ 1.7$ & $\$ 1.1$ & $\$ 6.5$ & $\$ 6.5$ \\
\hline SPP 1 & $\begin{array}{l}\text { Borrow Area to } \\
\text { Nassau SPP }\end{array}$ & 8 & $\$ 9$ & $1,000,000$ & $\$ 1.5$ & $\$ 3.1$ & $\$ 13.5$ & $\$ 1.7$ \\
\hline $\begin{array}{l}\text { NON } \\
\text { RSM } 1\end{array}$ & $\begin{array}{c}\text { Combined } \\
\text { Traditional NAV } \\
\text { and SPP Projects }\end{array}$ & & & & $\$ 3.2$ & $\$ 4.2$ & $\$ 20.0$ & $\$ 8.2$ \\
\hline RSM 1 & $\begin{array}{l}\text { Kings Bay to } \\
\text { Nassau SPP } \\
\text { North }\end{array}$ & 1 & $\$ 12$ & 237,000 & $\$ 1.7$ & $\$ 3.1$ & $\$ 7.2$ & $\$ 7.6$ \\
\hline *RSM 2a & $\begin{array}{l}\text { Kings Bay to } \\
\text { Nassau SPP } \\
\text { North }\end{array}$ & 1 & $\$ 12$ & 200,000 & $\$ 1.7$ & $\$ 3.1$ & $\$ 7.2$ & $\$ 7.2$ \\
\hline${ }^{*} \mathrm{RSM} 2 \mathrm{~b}$ & $\begin{array}{l}\text { Kings Bay to Ft. } \\
\text { Clinch }\end{array}$ & 1 & $\$ 14$ & 37,000 & & & $\$ 0.5$ & $\$ 0.5$ \\
\hline & $\begin{array}{l}\text { Combined Nassau } \\
\text { SPP and Ft. } \\
\text { Clinch placement }\end{array}$ & & & & & & & $\$ 7.7$ \\
\hline & \multicolumn{7}{|c|}{ RSM Value Strategy 1 and 2} & $\$ 0.5-\$ 0.6$ \\
\hline & NAV Benefit A & 1 & $\$ 2$ & 200,000 & & & $\$ 0.4$ & $\$ 0.4$ \\
\hline & OTHER Benefit A & 1 & $\$ 9$ & 28,000 & & & $\$ 0.3$ & $\$ 0.3$ \\
\hline & \multicolumn{7}{|c|}{ TOTAL Combined RSM Value Strategies 1-2 } & $\$ 1.2-\$ 1.3$ \\
\hline
\end{tabular}

-RSM value for strategies 1 and 2 is based on the removal of the traditional SPP, as sufficient beach quality material is placed on the beach from the NAV project, plus additional value associated with the cost of placement at the ODMDS relative to Nassau SPP North (NAV1 vs. RSM 1).

-Value for RSM 1 is split equally between NAV and FRM programs as NAV is required to mitigate the FRM project at $50 \%$.

-NAV Benefit A is calculated as the difference in cost per CY for placement of 200,000 CY on the beach versus ODMDS (\$14 - \$12).

-OTHER Benefit A is estimated based on the volume of sand placed on the beach from RSM $2 \mathrm{~b}$ (assuming $25 \%$ loss during placement) times the cost per cubic year from an offshore borrow source.

*RSM 2 is a combination of Fed-Fed and Fed-State projects as Ft. Clinch is a state park (placement per legal agreement with US Navy).

Individual dollar values for USACE Labor, Mobilization, Total Project Cost and Annualized Project Cost rounded to the nearest one hundred thousand for presentation purposes.

The Fort Pierce Harbor Navigation project and Fort Pierce SPP illustrate the value of one-time placement and life-cycle benefits associated with RSM projects (Table 3). Approximately 
200,000 CY of beach quality material from Fort Pierce Harbor is beneficially placed on the Fort Pierce SPP every 5 years at a cost of $\$ 1.3$ million per year (RSM 1). The value of placing $200,000 \mathrm{CY}$ of beach quality sand on the SPP at no cost to the SPP is $\$ 0.3$ million/year (NAV and FRM Benefit A), assuming $75 \%$ of the material is placed on the beach at an estimated cost of $\$ 9 /$ cubic yard. An additional value of $\$ 0.4$ million/year (NAV and FRM Benefit B) is attributed to the SPP based on the assumption that the 150,000 CY accounts for $28 \%$ of the material required to adequately maintain the SPP. The additional material increases the nourishment interval from 4 to 5 years, and reduces the price of the SPP from $\$ 1.8$ million/year to $\$ 1.4$ million/year for a life-cycle benefit of $\$ 0.4$ million/year. While the cost of placement on the beach is more expensive than placement at the ODMDS (NAV 1), the total cost of maintaining both the NAV and FRM projects provides $\$ 0.4$ million/year in value relative to the individual traditional projects (Non RSM 1). The benefits are attributed to both the NAV and FRM program due to required mitigation from downdrift impacts associated with the Fort Pierce Harbor project.

The total cost of permitting and maintaining ODMDS and DMMA sites was not included in this analysis.

Table 3. Summary of costs and value of beach quality material for project at Fort Pierce.

\begin{tabular}{|c|c|c|c|c|c|c|c|c|}
\hline $\begin{array}{l}\text { Project } \\
\text { Type }\end{array}$ & Source to Sink & $\begin{array}{c}\text { Interval } \\
(\mathrm{Yr})\end{array}$ & $\begin{array}{l}\$ \\
(\mathrm{CY})\end{array}$ & $\begin{array}{l}\text { Volume } \\
\text { (CY) }\end{array}$ & $\begin{array}{l}\text { USACE } \\
\text { Labor } \\
\text { (\$ M) }\end{array}$ & $\begin{array}{l}\text { Mobiliz- } \\
\text { ation } \\
(\$ M)\end{array}$ & $\begin{array}{c}\text { Total } \\
\text { Project } \\
\text { Cost } \\
(\$ \mathrm{M})\end{array}$ & $\begin{array}{c}\text { Annualized } \\
\text { Project } \\
\text { Cost } \\
(\$ \mathrm{M})\end{array}$ \\
\hline NAV 1 & $\begin{array}{c}\text { Ft. Pierce Harbor to } \\
\text { ODMDS }\end{array}$ & 5 & $\$ 17$ & 200,000 & $\$ 0.7$ & $\$ 0.8$ & $\$ 5.0$ & $\$ 1.0$ \\
\hline SPP 1 & $\begin{array}{l}\text { Offshore Borrow to } \\
\text { Ft. Pierce SPP }\end{array}$ & 4 & $\$ 9$ & 431,000 & $\$ 0.4$ & $\$ 2.8$ & $\$ 7.1$ & $\$ 1.8$ \\
\hline $\begin{array}{l}\text { Non } \\
\text { RSM } 1\end{array}$ & $\begin{array}{l}\text { Combined } \\
\text { Traditional NAV and } \\
\text { SPP Projects }\end{array}$ & & & & $\$ 1.1$ & $\$ 3.6$ & $\$ 12.1$ & $\$ 2.9$ \\
\hline RSM 1 & $\begin{array}{l}\text { Ft. Pierce Harbor to } \\
\text { Ft. Pierce SPP }\end{array}$ & 5 & $\$ 15$ & 200,000 & $\$ 0.7$ & $\$ 2.8$ & $\$ 6.4$ & $\$ 1.3$ \\
\hline & $\begin{array}{l}\text { NAV and FRM } \\
\text { Benefit A }\end{array}$ & & $\$ 9$ & 150,000 & & & $\$ 1.3$ & $\$ 0.3$ \\
\hline & $\begin{array}{l}\text { NAV and FRM } \\
\text { Benefit B }\end{array}$ & & & & & & & $\$ 0.4$ \\
\hline \multicolumn{8}{|c|}{ TOTAL Combined RSM Value Strategy 1} & $\$ 0.4$ \\
\hline
\end{tabular}

-RSM value for Strategy 1 was calculated by subtracting the cost of the NAV project from the RSM project and adding NAV and FRM Benefits A and B.

-NAV and FRM Benefit A was estimated based on the volume of sand placed on the beach from RSM 1 (assuming $25 \%$ loss during placement) times the cost per cubic year from an offshore borrow source.

-NAV and FRM Benefit B was estimated assuming the RSM project provides $28 \%$ of the needed volume to maintain shoreline protection at the SPP (120,000 CY of 431,000 CY every 4 years). The additional $28 \%$ of material would increase the project interval from 4 to 5 years and reduce the annual cost to $\$ 1.4$ million for a net value of $\$ 0.4$ million.

-Individual dollar values rounded to the nearest one hundred thousand for presentation purposes. 


\section{RESULTS}

SAD Overview. NAV and FRM projects managed by SAD were analyzed for economic and environmental efficiencies of placement and beneficial use of dredged material. Implementation of RSM principles provides an estimated \$97.3 million in annual value to SAD (Table 4). Based on data from NAV projects throughout the division, an estimated 62.4 million $\mathrm{CY}$ is dredged per dredge cycle, and $50 \%$ of the material is managed by RSM principles.

Of the NAV projects within SAD, the Charleston District (SAC) beneficially places the highest percentage of dredged material at $58 \%$, followed by the Mobile District (SAM) and the SAJ at $56 \%$ and 53\%, respectively (Table 4). Charleston Harbor provides the largest RSM value within SAD. Charleston Harbor accounts for $\$ 37.6$ million of the $\$ 38.9$ million total annual RSM value within SAC, with $91 \%$ of that value being attributed to the Cooper River Rediversion Project (CRRP). The CRRP rediverts flow (water and sediment) from the Cooper River back to its natural location on the Santee River. The second largest RSM value project within SAD is Mobile Harbor. Mobile Harbor provides $\$ 11.9$ million in RSM value primarily through utilization of TLP within Mobile Bay. The next three highest RSM value projects are in the SAJ (Tampa Harbor, Pinellas County Shallow Draft Inlets, and St. Augustine Inlet). These three projects provide SAJ a total annual RSM value of $\$ 13.1$ million through beneficial use of beach quality material. Other projects within SAD that provide over \$2 million in annual RSM value include Morehead City (Wilmington District [SAW]), Masonboro Inlet-Wrightsville Beach (SAW), Wilmington Harbor (SAW), Baker's Haulover (SAJ), Fort Myers (SAJ), and Pascagoula Harbor (SAM).

\section{Table 4. Total dredge volume (per dredge cycle) and value of RSM implemented through NAV-FRM projects in SAD.}

\begin{tabular}{|c|c|c|c|}
\hline \hline District & $\begin{array}{c}* \text { Total Dredge } \\
\text { Volume (CY) }\end{array}$ & $\begin{array}{c}\text { \% Managed by } \\
\text { RSM Strategies }\end{array}$ & $\begin{array}{c}\text { Annual RSM } \\
\text { Value (\$ M) }\end{array}$ \\
\hline SAD Total & $62,421,600$ & $50 \%$ & $\$ 97.3$ \\
\hline SAC Total & $17,726,100$ & $58 \%$ & $\$ 38.9$ \\
\hline SAJ Total & $10,027,000$ & $53 \%$ & $\$ 27.6$ \\
\hline SAM Total & $18,996,500$ & $56 \%$ & $\$ 18.3$ \\
\hline SAS Total** & $6,572,000$ & $4 \%$ & $\$ 0.0$ \\
\hline SAW Total & $9,100,000$ & $48 \%$ & $\$ 12.5$ \\
\hline *Total dredge volume calculated as the sum of all material dredged from NAV projects per dredge cycle.
\end{tabular}

**SAS refers to USACE Savannah District.

Table 4 indicates the SAD total volume per dredge cycle is approximately 62,421,600 CY. Figure 2 indicates approximately 50\% (31.2 million CY) of that total volume is managed through RSM principles. Of this 31.2 million CY managed through RSM principles, approximately $32 \%$ (10.0 million CY) is utilized for beach placement, approximately $28 \%$ ( 8.7 million CY) is utilized for nearshore placement, and approximately $40 \%$ (12.5 million CY) is utilized for estuarineriverine placement. The Wilmington District beneficially places the most material on beaches with a total volume per dredge cycle of 4.1 million CY, followed by the SAJ at 4.0 million CY. The SAM places the most material in nearshore environments, followed by the SAJ with total volumes of 6.5 and 1.6 million CY, respectively. Finally, the SAC beneficially places the most material in 
estuarine-riverine environments at 9.4 million $\mathrm{CY}$ per dredge cycle, followed by the SAM at 2.8 million CY.

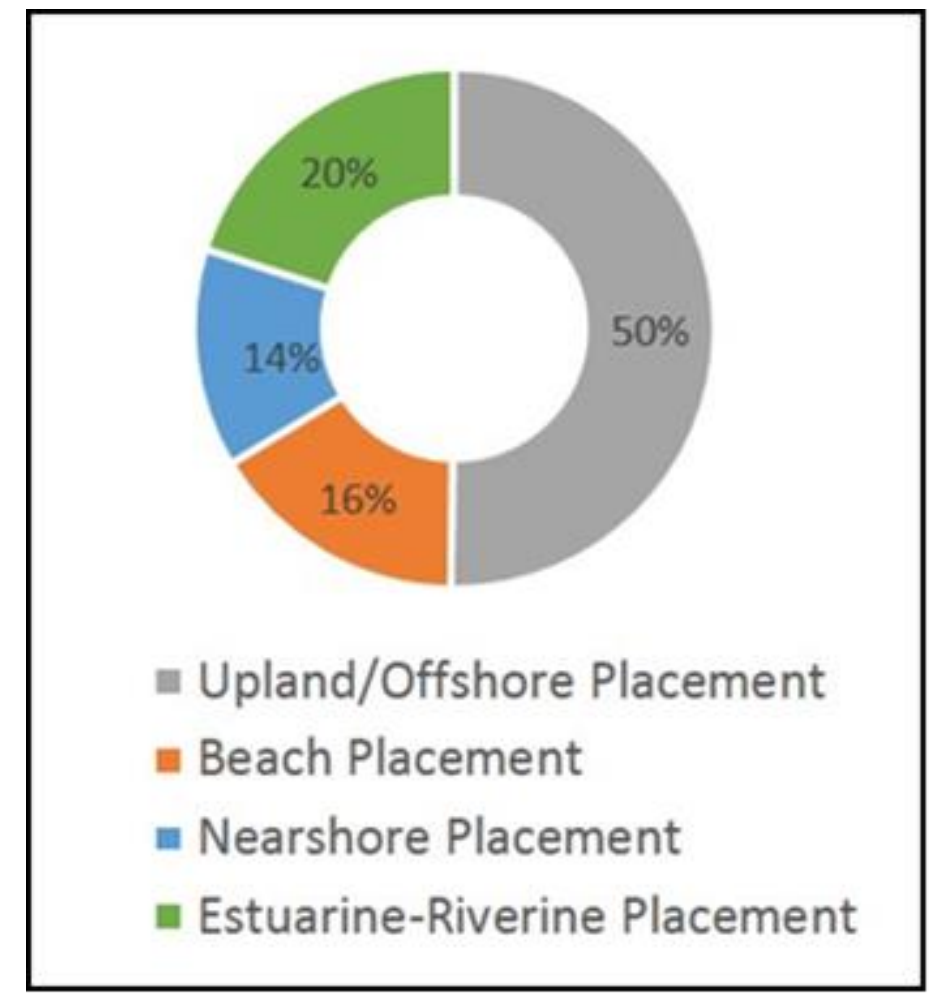

Figure 2. Distribution of placement by category for 62.4

million CY of material per dredge cycle from SAD

projects: Upland/Offshore placement -31.2

million CY; Beach Placement - 10.0 million $\mathrm{CY}$;

Nearshore Placement - 8.7 million $\mathrm{CY}$;

Estuarine/Riverine Placement - 12.5 million $\mathrm{CY}$.

The SAJ and SAW are efficient at placing beach quality sand on adjacent beaches, and utilizing navigation channels and inlets as borrow sources for FRM projects. The SAM is very efficient at utilizing TLP and open water placement as strategies to remove mud, silt, and clay material from NAV channels, as well as beneficially placing beach quality material from NAV channels onto adjacent beaches.

Most districts within SAD are efficient at placing beach quality sand from NAV channels onto adjacent beaches, but they are not as efficient at beneficially placing non-beach quality material (silty sand, mud, clay, rock) and use upland and offshore placement sites as the primary disposal method. The SAM executes several RSM strategies for placing non-beach quality material that includes open water placement and TLP. Open water and TLP are two strategies that are typically low-cost placement options that keep sediment in the active system and save capacity at upland and offshore disposal sites. While the SAM is located on the Gulf of Mexico and is hydrodynamically different from districts located on the Atlantic Ocean (lower tidal range, lower wave energy), open water placement and TLP could provide benefit if executed properly at other project sites throughout SAD. Wetland creation, hard-bottom habitat creation, and filling of relict dredge holes are other opportunities that could also be explored for this type of material. 
Nearshore placement of material is another area that could provide increased efficiency throughout SAD. Nearshore placement provides value, but primarily to the NAV program as a function of distance to other placement options. The FRM benefits are limited because nearshore placement areas often extend beyond the depth of closure, and the material is not placed in the littoral zone where it could provide shore protection benefits. Districts should consider prioritizing nearshore placement in the littoral zone for established placement areas, and for development of new placement areas. The Sediment Mobility Tool is a scoping-level tool found on the Navigation Portal (www.navigation.usace.army.mil) that could be used to identify potential nearshore placement site (McFall et al. 2016). Nearshore placement is an area of interest within the coastal engineering and research community and could become a more desirable option. Benefits include less equipment on the beach during placement, less impact to birds and nesting sea turtles, and less stringent silt and clay content limitations.

Dredge Fleet Assignment/Scheduling Optimization Model. Dredging conducted by USACE is scheduled largely on a project-by-project basis, with little-to-no coordination among managers across projects, districts, or divisions. Requests for bids from industry are announced according to local procurement schedules, effectively creating a situation where federal projects often compete against one another for the availability of the industrial dredging fleet. The end result is a situation where specific dredge plants are frequently traveling many hundreds of miles between consecutive projects, incurring millions of dollars of mobilization expenses, all in addition to the baseline costs of maintenance dredging. The resulting dredge season itineraries for particular dredge plants show inefficient paths, with dredges often bypassing projects while on their way to the next job, only to return to those same projects later in the dredging season. Figure 3A presents a hypothetical schematic based on representative dredge plant itineraries for SAD. In contrast, the Dredge Fleet Assignment/Scheduling Optimization Model (Nachtmann et al. 2014) developed in support of the RSM-OP seeks an idealized best-case dredging work plan with individual plants assigned to regionalized clusters of dredging projects, in conjunction with scheduling requirements that account for project dredging needs, dredge plant production rates, and the temporal constraints posed by environmental work restrictions. Figure 3B presents an idealized schematic of dredge plant paths illustrating coordinated sequenced job assignments and scheduling.

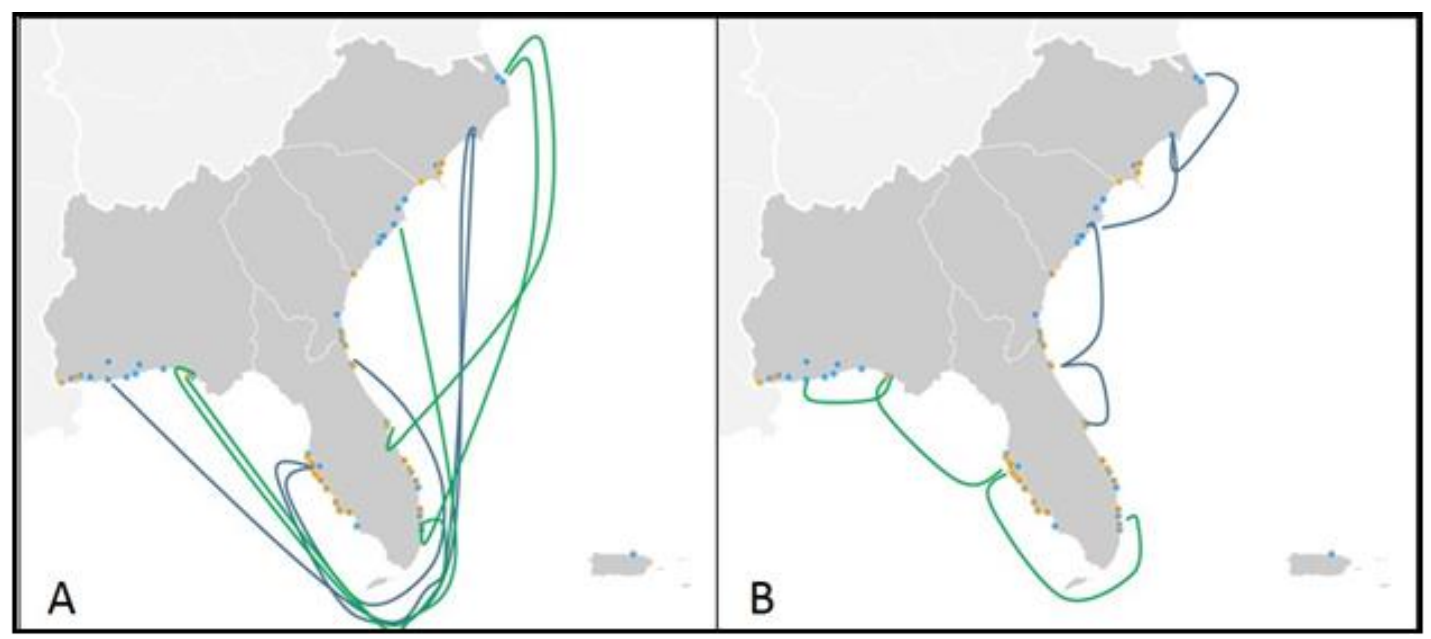

Figure 3. Two dredge plants with seasonal schedules indicated by colored paths (blue, and green) and SAD dredging project locations indicated by blue (NAV) and orange (FRM) circles. (Figure 3A. Schematic representation of an inefficient dredge plant seasonal itinerary. Figure 3B. Idealized seasonal dredge plant itinerary with optimal scheduling.) 
The idealized work plan ensures that all projects get dredged by assigning dredge plants with sufficiently high daily production rates such that the cubic yardage requirements for each project can be fully met within the respective environmental work windows. The model uses interval variables and a constraint programming approach, and by iteratively searching through the full solution space of possible assignment/scheduling combinations, the optimizer is able to maximize total production of the fleet while also minimizing the required travel times (and associated costs) between projects, thereby achieving the most efficient overall dredging work plan.

For the SAD dredge optimization model, project dredging data were compiled and used to populate the model input tables with 123 possible dredging projects across both NAV and FRM Business Lines with 35 environmentally restricted periods. Table 5 summarizes the distribution of dredging jobs and restricted periods across SAD projects. The list of dredging projects was compiled using records spanning several years, but this total number of projects is never actually conducted within a single dredging season. For model implementation purposes that cover a single year, the total number of projects was reduced to a more realistic 80-90 dredging jobs across SAD.

\begin{tabular}{||c|c|c||}
\hline \multicolumn{1}{||c|}{ Table 5. Distribution of dredging jobs and restricted periods within SAD. } \\
\hline District & $\begin{array}{c}\text { Number of } \\
\text { Dredging Jobs }\end{array}$ & $\begin{array}{c}\text { Number of Restricted } \\
\text { Periods }\end{array}$ \\
\hline Wilmington (SAW) & 13 & 4 \\
\hline Charleston (SAC) & 20 & 5 \\
\hline Savannah (SAS) & 9 & 9 \\
\hline Jacksonville (SAJ) & 48 & 17 \\
\hline Mobile (SAM) & 33 & 0 \\
\hline \hline
\end{tabular}

To define the theoretical dredge fleet for SAD, typical dredge plants were identified for each individual project to compile a model fleet that includes large, medium, and small hopper dredges; large, medium, and small pipeline dredges; and large and small mechanical dredges. Note that the modeled fleet of dredges was typically smaller than that employed across SAD during a single dredging season. This was done deliberately to shed as much insight as possible onto the combinations of projects that lend themselves to execution by the same unique dredge plant and that therefore represents potential candidates for regional contracting mechanisms.

The tradeoff associated with this reduced fleet modeling approach is that the output cannot be readily interpreted as a true dredging work plan for the entirety of SAD. Previous implementations of the Dredge Fleet Assignment/Scheduling Optimization Model (e.g., the west-coast hopper fleet) have used a simulated fleet that is more in line with that used in the real-world, thereby producing work plan solutions that can be more readily applied to USACE operations. Figure 4 provides an example of the work plan output generated in support of the RSM-OP. 


\begin{tabular}{|llllcl||}
\hline \multicolumn{1}{|c}{ Project } & \multicolumn{1}{c|}{ Vessel } & \multicolumn{1}{c|}{ Start } & Duration, days & End \\
Wilmington, various middle ch. Large Hopper 1 & 1-Oct-16 & 13 & 14-Oct-16 \\
Savannah, 0-24, ODMDS & Large Hopper 1 & 31-Oct-16 & 5 & 5-Nov-16 \\
Savannah, 0B-60B, ODMDS & Large Hopper 1 & 30-Nov-16 & 17 & 17-Dec-16 \\
Savannah, 0B-60B, nearshore & Large Hopper 1 & 17-Dec-16 & 4 & 21-Dec-16 \\
Charleston Entrance & Large Hopper 1 & 22-Dec-16 & 25 & 16-Jan-17 \\
Kings Bay, beach quality & Large Hopper 1 & 17-Jan-17 & 4 & 21-Jan-17 \\
Kings Bay, nearshore quality & Large Hopper 1 & 22-Jan-17 & 6 & 28-Jan-17 \\
Moorehead City Range CB & Large Hopper 1 & 30-Jan-17 & 19 & 18-Feb-17 \\
Port Everglades, Mgmt qua lity & Large Hopper 3 & 1-Oct-16 & 6 & 7-Oct-16 \\
Jax Harbor, nearshore quality & Large Hopper 3 & 8-Oct-16 & 5 & 13-Oct-16 \\
Mobile Bar, Sand Island & Large Hopper 3 & 19-Oct-16 & 15 & 3-Nov-16 \\
Mobile River, ODMDS & Large Hopper 3 & 4-Nov-16 & 5 & 9-Nov-16 \\
Gulfport Bar Channel & Large Hopper 3 & 10-Nov-16 & 3 & 13-Nov-16 \\
Gulfport Channel, ODMDS & Large Hopper 3 & 14-Nov-16 & 63 & 16-Jan-17 \\
Jax Harbor, Mgmt quality & Large Hopper 3 & 22-Jan-17 & 7 & 29-Jan-17 \\
Moorehead City, Range A & Large Hopper 3 & 1-Feb-17 & 6 & 7-Feb-17 \\
Town Creek, Inner & Medium Hopper 1 & 1-Oct-16 & 3 & 4-Oct-16 \\
Wilmington Baldhead Shoal & Medium Hopper 1 & 5-Oct-16 & 21 & 26-Oct-16 \\
Gulfport Anchorage Basin & Medium Hopper 1 & 2-Nov-16 & 64 & 5-Jan-17 \\
Pascagould Bar, ODMDS & Medium Hopper 1 & 6-Jan-17 & 23 & 29-Jan-17 \\
Mobile Bay, ODMDS & Medium Hopper 3 & 1-Oct-16 & 134 & 12-Feb-17 \\
Pascagould Inner Harbor & Medium Hopper 3 & 13-Feb-17 & 3 & 16-Feb-17 \\
\hline \hline
\end{tabular}

Figure 4. Example output from Dredge Fleet Assignment/Scheduling Optimization Model.

The color banding indicates those projects that are assigned to the same unique dredge plant within the modeled fleet. The start and end dates show the time of year that work is to take place at each respective locations. Summary diagnostics from the model allow program-level quantities such as total cubic yards dredged, total costs, total transportation costs, and average unit costs to be analyzed and compared for different fleet configurations and dredging requirement scenarios.

Analysis of historical dredging records for the 123 projects considered in this study indicates that mobilization costs can run from $16 \%$ to $21 \%$ of total dredging costs across all of SAD. With a combined annual dredging program (NAV and FRM) on the order of $\$ 250$ million, this indicates that total SAD mobilization expenditures can range from $\$ 40$ to $\$ 53$ million per year. Dredge travel costs assumed for the purposes of the model simulations were $\$ 500$ to $\$ 1,000$ per mile for hopper dredges depending on size, $\$ 1,000$ to $\$ 1,500$ per mile for pipeline dredges depending on size, and $\$ 800$ to $\$ 1,200$ per mile for mechanical dredges depending on size. When these values are applied to the optimized dredge schedules generated by the model, the total SAD-wide dredge mobilization costs are reduced to between $5 \%$ to $8 \%$ of total dredging costs. With the reduced mobilization costs as a percentage of total dredging expenditures, the dredge fleet scheduling model indicates tangible savings in the range of \$20 to \$40 million annually if applied across all of SAD. These results indicate tremendous potential to improve overall program efficiency; however, several important federal contractual considerations will need to be addressed before results can be implemented. 
CONCLUSIONS: The South Atlantic Division Optimization Pilot developed a methodology to efficiently execute NAV and FRM business line budgets and maximize dredging through application of RSM principles. Based on the project optimization analysis and dredge fleet assignment/scheduling optimization model, nearly $\$ 100$ million in annual value was calculated for the SAD. In addition, the analyses identified numerous opportunities to more efficiently execute projects and manage regional dredging contracts.

ADDITIONAL INFORMATION. This USACE Regional RSM-TN was prepared as part of the USACE RSM Program managed by the US Army Engineer Research and Development Center, Coastal and Hydraulics Laboratory, Vicksburg, MS. Additional information pertaining to the RSM Program may be obtained from the RSM website (http://rsm.usace.army.mil) or from the USACE National RSM Program Manager, Dr. Katherine Brutsché Katherine.E.Brutsche@ usace.army.mil. Questions regarding this RSM-TN can be addressed to Dr. Clay McCoy, 904-232-3657 Clay.A.McCoy@usace.army.mil, Deputy Director, Regional Sediment Management Regional Center of Expertise, US Army Engineer District, Jacksonville.

This ERDC/TN RSM-20-7 should be cited as follows:

McCoy, C. A., J. J. Keiser, K. N. Mitchell, and Linda S. Lillycrop. 2020. South Atlantic Division Regional Sediment Management Optimization Pilot. ERDC/TN RSM-20-7. Vicksburg, MS: US Army Engineer Research and Development Center. http://dx.doi.org/10.21079/11681/37969

\section{REFERENCES}

McFall, Brian C., S. Jarrell Smith, Cheryl E. Pollock, James Rosati III, and Katherine E. Brutsché. 2016. Evaluating Sediment Mobility for Siting Nearshore Berms. ERDC/CHL CHETN-IV-108. Vicksburg, MS: US Army Engineer Research and Development Center.

Nachtmann, Heather, Kenneth N. Mitchell, Chase E. Rainwater, Ridvan Gekik, and Edward A. Pohl. 2014. "Optimal Dredge Fleet Scheduling within Environmental Work Windows." Transportation Research Record: Journal of the Transportation Research Board. No. 2466. Washington, DC: Transportation Research Board of the National Academies.

National Ocean Economics Program. 2015. http://oceaneconomics.org/nonmarket

Pendleton, Linwood. 2009. The Economic and Market Value of Coasts and Estuaries: What's at Stake? Produced by Restore America's Estuaries.

https://www.habitat.noaa.gov/pdfleconomic and market_valueofcoasts and estuaries.pdf

Smith, M., D. de Groot, D. Porrot-Maite, and G. Bergkamp. 2006. Pay: Establishing Payments for Watershed Services. Gland, Switzerland: International Union for Conservation of Nature. https://www.iucn.org/content/pay-establishing-payments-watershed-services-1

NOTE: The contents of this technical note are not to be used for advertising, publication, or promotional purposes. Citation of trade names does not constitute an official endorsement or approval of the use of such products. 